\title{
Pulmonary veno-occlusive disease after bone marrow transplantation
}

\author{
X TROUSSARD, JF BERNAUDIN, C CORDONNIER, J FLEURY, D PAYEN, J BRIERE, \\ JP VERNANT
}

From the Service d'Hématologie Clinique, Département de Pathologie, and Service de Réanimation Médicale, Hopital Henri Mondor, Creteil; and the Service d'Hématologie Clinique, Centre Hospitalier de Brest, Brest, France

Pulmonary veno-occlusive disease is a very rare pulmonary vascular disease and has not previously been described after bone marrow transplantation. We report the case of a 12 year old boy who developed pulmonary veno-occlusive disease after bone marrow transplantation for acute lymphoblastic leukaemia.

\section{Case report}

A 7 year old white boy who had previously been healthy was admitted to hospital in 1978 with acute lymphoblastic leukaemia. Complete remission was obtained with vincristine $(2 \mathrm{mg})$, cyclophosphamide $(600 \mathrm{mg})$, daunorubicin (35 mg daily on days 1,2 , and 3) and cytarabine (70 mg daily on days 1,2 , and 3 ). Maintenance treatment was continued.

Five years later (1983) he suffered a relapse: a second complete remission was obtained with four injections of vincristine $(2.5 \mathrm{mg})$ and prednisone. Appreciable hypercalcaemia of $4.6 \mathrm{mmol} / \mathrm{l}(180 \mathrm{mg} / \mathrm{l})$ was observed; it was reduced with mithramycin, and disappeared during remission.

Five months later a second relapse occurred, also associated with hypercalcaemia of $3.5 \mathrm{mmol} / \mathrm{l}(140 \mathrm{mg} / \mathrm{l})$. A course of chemotherapy with vincristine $(2.5 \mathrm{mg})$, prednisone, cyclophosphamide (700 $\mathrm{mg})$, and daunorubicin (40 mg) was started. Complete remission could not be achieved, and it was decided to perform a marrow transplant, although $15 \%$ blast cells were observed in the bone marrow. The hypercalcaemia was again reduced with mithramycin. Until this time there had been no signs of respiratory disease and the chest radiographs had been normal throughout.

An allograft was performed with engraftment from his sister, who had homologous leucocytic antibodies, after conventional preparation with combination of cyclophosphamide ( $60 \mathrm{mg} / \mathrm{kg}$ on days 5 and 4$)$ and total body irradiation of $10 \mathrm{~Gy}(1000 \mathrm{rad})$ with pulmonary shielding above $8 \mathrm{~Gy}(800 \mathrm{rad})$. Methotrexate was given on days $1(20 \mathrm{mg})$, $3(13 \mathrm{mg})$, and $6(13 \mathrm{mg})$ as prophylaxis against graft versus host disease but prednisone $(1 \mathrm{mg} / \mathrm{kg}$ ) was required on day 18 for grade 1 graft versus host disease.

Address for reprint requests: Dr JF Bernaudin, Service d'Histologie, Hôpital Henri Mondor, 94010 Creteil Cedex, France.

Accepted 10 August 1984
The transplanted marrow engrafted on day 22. Bacterial pneumonia (Pseudomonas aeroginosa) developed in the left lower lobe on day 32 and resolved incompletely with cefsulodin ( $3 \mathrm{~g}$ daily for 10 days).

On day 40 he complained of abdominal pain and examination showed peripheral oedema, ascites, and hepatosplenomegaly. The conjugated bilirubin concentration was 76 (normal <8) $\mu \mathrm{mol} / \mathrm{l}(444$ (normal <46.8) mg/100 ml), alkaline phosphatase activity 158 (normal <200) IU/l, serum aspartate aminotransferase activity 64 (normal $<18)$ IU/l, and serum glutamic pyruvate transaminase activity 120 (normal <25) IU/l.

On day 44 interstitial pneumonitis, predominantly affecting the right lung, developed. No cardiac abnormalities were observed on the chest radiograph or electrocardiogram. Bronchoalveolar lavage performed in the right pyramidal segment showed numerous siderophages. His respiratory state grew worse, and he died from respiratory failure despite ventilatory help. A postmortem "biopsy" of the right lower lobe was performed within an hour after death. A full necropsy was not possible, and the heart and liver could not be examined.

Histological sections were stained with haematoxylineosin, orcein, Masson's trichrome, Perls's and von Kossa's stains. The most striking lesion was eccentric intimal fibrosis of most of the pulmonary veins observed. The small intralobular veins were regularly narrowed. The interlobular veins were also narrowed (fig 1) and some were totally occluded by the intimal fibrosis (fig 2). No intraluminal thrombi were observed. The intimal fibrosis was composed of loose myxoid, finely fibrillar, tissue containing few cells; in particular, no inflammatory cells were observed. No hypertrophy or arterialisation of the media was observed in medium sized pulmonary veins. Elastic fibres of the media were enlarged, fragmented, and encrusted with calcium without iron. Medial hypertrophy was seen in some muscular pulmonary arteries, and a few recent thrombi were also observed, but no major arterial changes were present.

\section{Discussion}

Although the clinical signs and the electrocardiographic pattern were not suggestive of pulmonary hypertension, the presence of numerous siderophages in the bronchoalveolar lavage and the histological findings confirm the diagnosis of pulmonary veno-occlusive disease. Pulmonary 


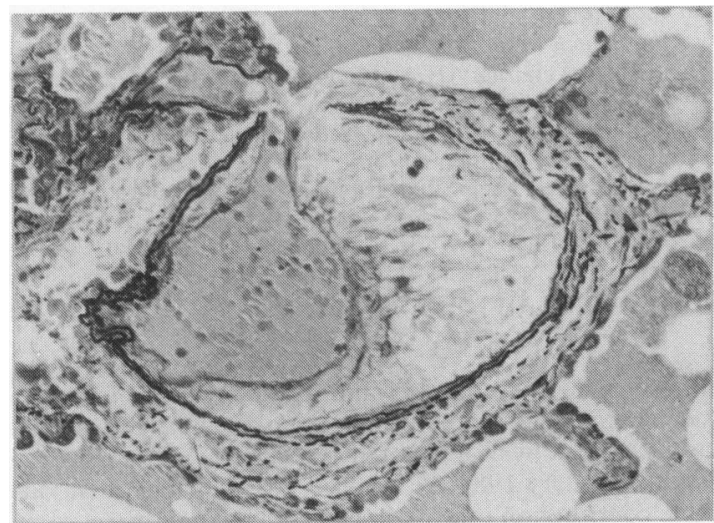

Fig 1 Interlobular pulmonary vein narrowed by eccentric intimal fibrosis. (Orcein, $\times 320$.)

veno-occlusive disease has rarely been described, and its pathogenesis remains unknown. Infectious agents, ${ }^{1-3}$ familial factors, ${ }^{4}$ and deposition of immune complexes ${ }^{5}$ have been implicated. Recently, a case of pulmonary veno-occlusive disease occurring after chemotherapy (bleomycin, mitomycin, cisplatin) was reported. ${ }^{6}$ Pulmonary veno-occlusive disease has not previously been reported after marrow transplantation, but hepatic venoocclusive disease is well recognised in this situation, ${ }^{78}$ and there may be a common pathogenesis. Although histological examination of the liver was not possible in our patient, liver function was appreciably abnormal.

Possible actiological factors in the present case included irradiation, multiple chemotherapy, and acute graft versus host disease. The intrapulmonary calcification was probably a result of the hypercalcaemia observed during the course of leukaemia.

We thank N Relin, S Daude, and S Mousky for their technical help.

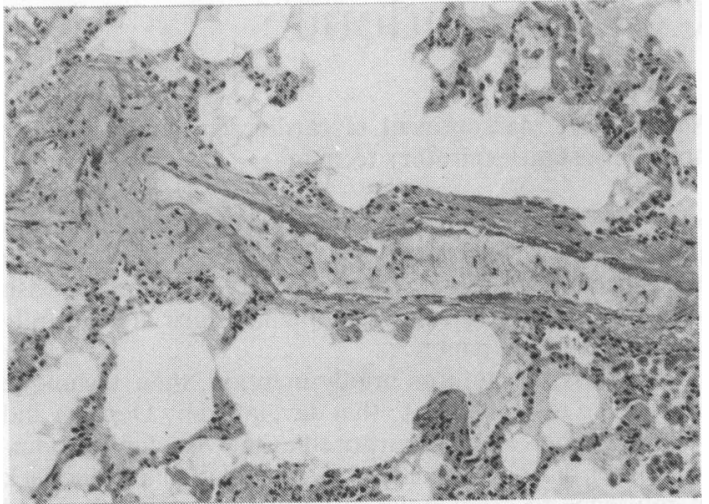

Fig 2 Interlobular pulmonary vein almost completely occluded by finely fibrillar tissue. $(\times 125$, Iron haematoxylin and eosin stain.)

\section{References}

1 Heath D, Scott O, Lynch J. Pulmonary veno-occlusive disease. Thorax 1971;26:663-74.

2 Pajewski M, Reif R, Manor H, Starinsky R, Katzir D. Pulmonary veno-occlusive disease in a unilateral hypertransradiant lung. Thorax 1981;36:397-9.

3 Thadany V, Burrow C, Whitaker W, Heath D. Pulmonary veno-occlusive disease. $Q J$ Med 1975;44:133-59.

4 Voordes CG, Kuipers JRG, Elema JD. Familial pulmonary veno-occlusive disease: a case report. Thorax 1977;32:763-6.

5 Corrin G, Spencer H, Turner-Warwick M, Beales SJ, Hamblin JJ. Pulmonary veno-occlusion-an immune complex disease? Virchows Arch [Pathol Anat] 1974;364:81-91.

6 Joselson R, Warnock M. Pulmonary veno-occlusive disease after chemotherapy. Hum Pathol 1983; 14:88-91.

7 Shulman H, McDonald GB, Matthews D, et al. An analysis of hepatic veno-occlusive disease and centrolobular hepatic degeneration following bone marrow transplantation. Gastroenterology 1980;79:1178-91.

8 Zafrani ES, Pinaudeau Y, Dhumeaux D. Drug induced vascular lesions of the liver. Arch Intern Med 1983;143:495-502. 